\title{
Japanese University Teachers' Depression Status and Its Influence Factors
}

\author{
Mika Kataoka', Kazuhiro Ozawa², Tetsuya Tanioka ${ }^{3}$, Toyohiko Kodama1, \\ Yuko Tamura', Beth King ${ }^{4}$ \\ ${ }^{1}$ Department of Nursing, Mie University Graduate School of Medicine, Mie, Japan \\ ${ }^{2}$ Gifu College of Nursing, Gifu, Japan \\ ${ }^{3}$ Divisions of Health Sciences, Institute of Biomedical Sciences, Tokushima University Graduate School, Tokushima, Japan \\ ${ }^{4}$ Christine E. Lynn College of Nursing, Florida Atlantic University, Boca Raton, USA \\ Email: mika3@nurse.medic.mie-u.ac.jp
}

How to cite this paper: Kataoka, M., Ozawa, K., Tanioka, T., Kodama, T., Tamura, Y. and King, B. (2017) Japanese University Teachers' Depression Status and Its Influence Factors. Open Journal of Psychiatry, 7, 186-198.

https://doi.org/10.4236/ojpsych.2017.73017

Received: May 26, 2017

Accepted: July 24, 2017

Published: July 27, 2017

Copyright (C) 2017 by authors and Scientific Research Publishing Inc. This work is licensed under the Creative Commons Attribution International License (CC BY 4.0).

http://creativecommons.org/licenses/by/4.0/

\begin{abstract}
Risk factors of the depression are the occupational stress. The mental health condition of university teachers who participate in the socialization of diverse students is an important issue; however, there are few studies on depression among university teachers. The purpose of this study is to clarify Japanese university teachers' depression status assessed by the Patient Health Questionnaire-9 and its influence factors: Japanese university teachers' depression status depression status, personal background, job situation, social support, and stress coping behavior. The self-administered questionnaire survey was mailed to 924 university teachers in Japan, with a survey return rate of $43.8 \%$ $(\mathrm{N}=405)$. A total of 342 surveys were completed and valid. The Patient Health Questionnaire 9 (PHQ-9), Multidimensional Scale of Perceived Social Support (MSPSS), the Japanese version of the Brief Coping Orientation to Problems Experienced (COPE) and the Work Situation Questionnaire (WSQ) were analyzed to clarify the depression status and its influence factors. Multivariate logistic regression analysis was used to examine factors related to the major depression. The subjects included 274 men (80.1\%) and 68 women (19.9\%), 105 professors (30.7\%), 52 associate professors (15.2\%), 53 lecturers (15.5\%) and 132 assistants (38.6\%). The subjects' mean of age and teaching experiences were $44.1 \pm 9.7$ years, $15.6 \pm 10.1$ years. The mean PHQ score was $3.9 \pm 4.1$, and 307 subjects $(89.8 \%)$ were 0 - 9 points and 35 subjects $(10.2 \%)$ were over 10 points (10 points or over). For women [OR $=7.009,95 \% \mathrm{CI}$ $2.387-20.584 ; \mathrm{p}<0.001]$, religion $[\mathrm{OR}=1.813,95 \%$ CI $1.175-2.798 ; \mathrm{p}=$ 0.007], self-blame [OR $=1.808,95 \%$ CI $1.280-2.556 ; \mathrm{p}=0.001]$, substance use [OR $=1.453,95 \%$ CI $1.103-1.913 ; \mathrm{p}=0.008]$ were risk factors of depression status. On the other hand, high job satisfaction level [OR $=0.945,95 \% \mathrm{CI}$ $0.921-0.969 ; \mathrm{p}<0.001]$, higher age $[\mathrm{OR}=0.927,95 \%$ CI $0.873-0.984 ; \mathrm{p}=$
\end{abstract}


0.014], use of instrumental support [OR $=0.622,95 \%$ CI $0.399-0.969 ; \mathrm{p}=$ $0.036]$, and use of social support [OR $=0.588,95 \%$ CI $0.376-0.921 ; \mathrm{p}=$ 0.020] were factors that reduced the risk of depression. These findings suggested that in order to improve the depression status of university teachers, and to develop mental health measures for university faculty members based on such risk factors are necessary in the future.

\section{Keywords}

Depression, University Teachers, Mental Health, Japan

\section{Introduction}

Depression is one of the leading causes of disease burden worldwide. Particularly, depression is not only the most common mental disorder in general practice as well as mental health settings, but also is a major public health problem. Unipolar depression is the second cause of disability-adjusted life years [1]. In 2013, the Japanese Ministry of Health, Labor, and Welfare identified psychiatric disease as one of the "Japan's 5 major diseases" and launched a high-priority policy for disease control and prevention [2]. Lancet reports that depression is a main factor of years lived with disability [3]. Japan Ministry of Health, Labour and Welfare in 2014 [4], reported the number of depression in Japan was 1,116,000 and the data demonstrate an upward trend.

Risk factors of the depression are the occupational stress. Teaching and research performance in the University are directly related to a teachers' promotion [5] [6] [7] [8]. In Japan, the number of teaching staff of a university and the junior college who resignation to depression was 44 , this datum has been reported by the Ministry of Education, Culture, Sports, Science and Technology, in 2012 [9]. The mental health condition of university teachers who participate in the socialization of diverse students is an important issue; however, there are few studies on depression among university teachers [10].

For depression, it is important that an individual notices the mental and physical abnormality of own early and precise screening is necessary. Miki reports that approximately $65 \%$ of depression patients consulted internal medicine first [11]. In the absence of systematic screening, however, family physicians could not diagnose at least $50 \%$ of cases of major depression [12]. There are some screening tool for detecting depression; Self-rating Depression Scale (SDS), Self-Rating Questionnaire for Depression(SRQ-D), Center for Epidemiologic Studies Depression Scale(CES-D), Hospital Anxiety and Depression Scale (HADS), WHO(Five)Well-Being Index(WHO-5), and The 9-item Patient Health Questionnaire (PHQ-9) [13] [14] [15] [16], and those are instrument for making criteria-based diagnoses of depressive and other mental disorders commonly encountered in primary care. Especially, the PHQ-9 is a reliable and valid measure of depression severity. 
The purpose of this study is to clarify Japanese university teachers' depression status assessed by the Patient Health Questionnaire-9 and its influence factors: Japanese university teachers' depression status, personal background, job situation, social support, and stress coping behavior.

\section{Methods}

\subsection{Subjects}

This study performed the complete survey of the Japanese a university. This university has about 1900 staff members, five faculties, six graduate schools, and some institutes and a hospital. Subjects work for the arts and sciences, engineering, medicine, dentistry, and pharmaceutical. There were 924 university teachers working in this university and 405 questionnaire copies returned yielding a response rate of $43.8 \%$. With some questionnaire copies not completely filled out, only data from 342 respondents were used and analyzed.

\subsection{Survey Methods}

The self-administered questionnaire survey was mailed and returned during the months of November 2010 to January 2011.

\subsection{Instruments}

The following instruments were used for data collection:

1) Individual parameters survey form with data about gender, age, professional position, and length of teaching experience.

2) The Work Situation Questionnaires (WSQ) [17], consisted of questions related to working hours, hours of homework per week, conditions of taking paid leave, job satisfaction and job control level.

3) PHQ-9: The PHQ-9 [13] [14] [15] [16] has been recommended for depression screening in primary care [18] [19]. The Patient Health Questionnaire (PHQ), developed from the original Primary Care Evaluation of Mental Disorders, is a self-administered version used for making criterion-based diagnoses of mental disorder common in primary care [20]. The PHQ-9 is the 9-item depression module from the full PHQ. The PHQ-9 has been developed from the original PRIME-MD PQ (Patient Questionnaire). The PHQ-9 can evaluate the nine Diagnostic and Statistical Manual of Mental Disorders, Fourth Edition (DSMIV) criteria for major depressive disorder (MDD). The validity of PHQ-9 is proved for an evaluation index of the depression diagnosis by the studies that screening of depression of chronic physical patient and the elderly person [21] [22] [23] [24]. The diagnosis of major depressive disorder (MDD) can be made by a categorical algorithm using these nine items. Other depressive disorder (ODD) is diagnosed if 2, 3, or 4 depressive symptoms have been present at least "more than half the days in past 2 weeks. As a severity measure, the PHQ-9 can be assessed by calculating a summary score. Next, we also measured the severity of depressive states according to the total score of J-PHQ-9 at the second stage, the score is ranging from 0 to 27 , and the points of $1-4,5-9,10-14,15-19,20$ 
- 27 respectively represent minimal, mild, moderate, moderate-severe, and severe state of depressive symptoms. A score 10 points or over was considered as major depression [14].

4) Social support perceived by the teachers was assessed using the Japanese version of Multidimensional Scale of Perceived Social Support (MSPSS) [25] [26] [27] [28]. Total and subscores range from 1 to 7, with higher scores suggesting greater levels of perceived social support.

5) The coping style of the teachers was assessed using the Japanese short version of brief Coping Orientation to Problems Experienced (COPE) [29] [30] [31]. Sub-scores range from 1 to 8 , with higher scores suggesting greater levels of used coping skills.

\subsection{Data Analysis}

Participant with PHQ-9 scores using cut-off 10 or greater were classified as likely to meet criteria for moderate or more severe depressive disorder.

Descriptive statistics for the research variables of individual parameters, work situation (WSQ), social support (MSPSS total and 3 sub-scores), and coping styles (14 sub-scores of Brief COPE) were calculated.

Relationship among individual parameters, work situation, social support, and coping styles and major depression were analyzed by multivariate logistic regression analysis using backward stepwise selection of variables with p-value < 0.05. Data were analyzed using IBM SPSS Statistics Version 24.0 for Windows. A p-value of less than 0.05 was considered statistically significant.

\subsection{Ethical Considerations}

This research was approved by the University of Tokushima hospital clinical study Ethical Review Board (approval number 1032). No harm could be identified to the subjects. Return of the survey implied consent by the subjects. Subjects were notified that privacy would be protected as only aggregate data would be utilized in reporting of findings.

\section{Results}

\subsection{Demographic Data}

The subjects' characteristics were shown in Table 1 . The subjects included 274 men $(80.1 \%)$ and 68 women (19.9\%), 105 professors $(30.7 \%), 52$ associate professors (15.2\%), 53 lecturers (15.5\%) and 132 assistants (38.6\%). The subjects' mean of age and teaching experiences were $44.1 \pm 9.7$ years, $15.6 \pm 10.1$ years.

The mean PHQ score was $3.9 \pm 4.1$, and 307 subjects $(89.8 \%)$ were 0 - 9 points and 35 subjects $(10.2 \%)$ were 10 points or over.

In the WSQ, the subjects worked for an average of $60.7 \pm 16.9$ hours per week, the job satisfaction level was $63.0 \% \pm 17.9 \%$, and job control level was $60.3 \% \pm$ $19.7 \%$.

In the MSPSS total score, and MSPSS sub-scores; family subscale, significant 
Table 1. The subjects' characteristics.

\begin{tabular}{|c|c|c|c|c|c|}
\hline \multirow{2}{*}{ Variables } & & & \multicolumn{3}{|c|}{ Patient Health Questionnaire (PHQ-9) } \\
\hline & & & Total $(\mathrm{n}=342)$ & $0-9(\mathrm{n}=307)$ & $10-27(\mathrm{n}=35)$ \\
\hline \multicolumn{3}{|c|}{ Patient Health Questionnaire (PHQ-9) } & $3.9 \pm 4.1$ & $307(89.8)$ & $35(10.2)$ \\
\hline \multirow{9}{*}{ Individual Parameters } & Gender & Men & $274(80.1)$ & $256(93.4)$ & $18(6.6)$ \\
\hline & & Women & $68(19.9)$ & $51(75.0)$ & $17(25.0)$ \\
\hline & Age (yrs) & & $44.1 \pm 9.7$ & $44.5 \pm 9.8$ & $40.6 \pm 8.5$ \\
\hline & Professional & sition & & & \\
\hline & & Professor & $105(30.7)$ & $99(94.3)$ & $6(5.7)$ \\
\hline & & Associate professor & $52(15.2)$ & $48(92.3)$ & $4(7.7)$ \\
\hline & & Lecturer & $53(15.5)$ & $46(86.8)$ & $7(13.2)$ \\
\hline & & Assistant & $132(38.6)$ & $114(86.4)$ & $18(13.6)$ \\
\hline & Teaching exp & riences (yrs) & $15.6 \pm 10.1$ & $16.0 \pm 10.2$ & $12.3 \pm 8.6$ \\
\hline \multirow[t]{9}{*}{ Work Situation (WSQ) } & Working hou & s per week & $60.7 \pm 16.9$ & $60.7 \pm 15.9$ & $61.1 \pm 24.6$ \\
\hline & Homework & Yes & $235(68.7)$ & $210(89.4)$ & $25(10.6)$ \\
\hline & & No & $107(31.3)$ & $97(90.7)$ & $10(9.3)$ \\
\hline & Conditions o & taking paid leave & & & \\
\hline & & Always & $50(14.6)$ & $50(100)$ & $0(0)$ \\
\hline & & Often & $137(40.1)$ & $121(88.3)$ & $16(11.7)$ \\
\hline & & Seldom & $155(45.3)$ & $136(87.7)$ & $19(12.3)$ \\
\hline & Job satisfacti & level (\%) & $63.0 \pm 17.9$ & $65.2 \pm 16.1$ & $43.6 \pm 21.1$ \\
\hline & Job control le & el (\%) & $60.3 \pm 19.7$ & $62.3 \pm 18.3$ & $43.3 \pm 23.5$ \\
\hline \multirow[t]{4}{*}{ Social Support (MSPSS) } & Total scores & & $5.26 \pm 1.05$ & $5.35 \pm 0.96$ & $4.50 \pm 1.41$ \\
\hline & & Family subscale & $5.61 \pm 1.17$ & $5.68 \pm 1.11$ & $5.02 \pm 1.50$ \\
\hline & & Significant other subscale & $5.35 \pm 1.19$ & $5.45 \pm 1.11$ & $4.43 \pm 1.48$ \\
\hline & & Friends subscale & $4.83 \pm 1.20$ & $4.92 \pm 1.11$ & $4.04 \pm 1.61$ \\
\hline \multirow[t]{14}{*}{ Coping styles (COPE) } & & Self-distraction & $4.65 \pm 1.28$ & $4.56 \pm 1.28$ & $5.40 \pm 1.09$ \\
\hline & & Active coping & $5.68 \pm 1.02$ & $5.74 \pm 1.02$ & $5.23 \pm 0.88$ \\
\hline & & Denial & $2.62 \pm 0.89$ & $2.59 \pm 0.88$ & $2.86 \pm 1.00$ \\
\hline & & Substance use & $3.51 \pm 1.66$ & $3.43 \pm 1.58$ & $4.23 \pm 2.13$ \\
\hline & & Use of emotional support & $4.60 \pm 1.37$ & $4.62 \pm 1.35$ & $4.46 \pm 1.52$ \\
\hline & & Use of instrumental support & $4.88 \pm 1.31$ & $4.93 \pm 1.31$ & $4.43 \pm 1.27$ \\
\hline & & Behavioral disengagement & $3.60 \pm 1.02$ & $3.54 \pm 1.01$ & $4.06 \pm 1.00$ \\
\hline & & Venting & $4.39 \pm 1.21$ & $4.38 \pm 1.20$ & $4.54 \pm 1.22$ \\
\hline & & Positive reframing & $5.23 \pm 1.18$ & $5.21 \pm 1.18$ & $5.37 \pm 1.21$ \\
\hline & & Planning & $6.12 \pm 1.03$ & $6.16 \pm 1.01$ & $5.74 \pm 1.12$ \\
\hline & & Humor & $4.00 \pm 1.32$ & $4.03 \pm 1.29$ & $3.74 \pm 1.58$ \\
\hline & & Acceptance & $6.05 \pm 0.92$ & $6.07 \pm 0.93$ & $5.86 \pm 0.81$ \\
\hline & & Religion & $3.01 \pm 1.13$ & $2.97 \pm 1.11$ & $3.29 \pm 1.20$ \\
\hline & & Self-blame & $4.27 \pm 1.28$ & $4.15 \pm 1.22$ & $5.37 \pm 1.35$ \\
\hline
\end{tabular}

Work Situation Questionnaires (WSQ), Patient Health Questionnaire (PHQ-9), Multidimensional Scale of Perceived Social Support (MSPSS), brief Coping Orientation to Problems Experienced (COPE), and Standard deviation (SD). 
other subscale, and friends subscale were $5.26 \pm 1.05,5.61 \pm 1.17,5.35 \pm 1.19$, and $4.83 \pm 1.20$.

The high score of coping style were Planning (6.12 \pm 1.03$)$, Acceptance (6.05 \pm 0.92), Active coping (5.68 \pm 1.02$)$, and Positive reframing (5.23 \pm 1.18$)$.

\subsection{The Relationship among Depression, Parameters, Social Support, and Coping Styles}

Table 2 shows the adjusted odds ratio (OR) and 95\% confidence interval (CI) for each major depression variable. Following were significantly related to major depression: For women $[\mathrm{OR}=7.009,95 \%$ CI $2.387-20.584 ; \mathrm{p}<0.001]$, religion $[\mathrm{OR}=1.813,95 \% \mathrm{CI} 1.175-2.798 ; \mathrm{p}=0.007]$, self-blame $[\mathrm{OR}=1.808,95 \% \mathrm{CI}$ $1.280-2.556 ; \mathrm{p}=0.001]$, substance use $[\mathrm{OR}=1.453,95 \%$ CI $1.103-1.913 ; \mathrm{p}=$ 0.008 ] were risk factors of depression status.

On the other hand, high job satisfaction level [OR $=0.945,95 \%$ CI 0.921 $0.969 ; \mathrm{p}<0.001]$, higher age $[\mathrm{OR}=0.927,95 \%$ CI $0.873-0.984 ; \mathrm{p}=0.014]$, use of instrumental support [OR $=0.622,95 \%$ CI $0.399-0.969 ; \mathrm{p}=0.036$ ], and use of social support $[\mathrm{OR}=0.588,95 \%$ CI $0.376-0.921 ; \mathrm{p}=0.020]$ were factor that reduced the risk of depression.

\section{Discussion}

In this study, $10.2 \%$ of the subjects had a PHQ score $\geq 10$ points, and they were judged to be at a high risk for depression. The other population-based studies report the proportion with a score of 10 points or more to be $8.6 \%$ in the USA [32] and 9.2\% in Germany [21]. Our survey subjects had a slightly to severe depressive symptoms, compared to these populations. According to Haratani et al.'s survey [33] among 3991 Japanese workers (men: 1984, women: 2007) of diverse occupations and age groups, the proportion of those with a PHQ score $\geq$ 10 points was $18.3 \%$. In the teachers' survey in the U.K (men: 220 , women: 335 ) report the proportion with a score of 10 points or more was $19.4 \%$ [34]. Thus, it was thought that the percentage of high risk for depression found in our study is small in comparison with UK data.

Haratani et al.'s survey [33] reported that women had higher PHQ scores in all age groups.

Generally, the prevalence of women depression is higher than that of men, and according to the study by Kawakami et al. [35], the prevalence of women depression was about twice that of men was. However, our analysis revealed that women are seven times more at risk of developing depression than men are, and it can be considered extremely high. The proportion of women university teachers is very small in Japan, and it was $18.2 \%$ in 2007 [36]. Given that a survey report [37] claims that the suicide rate of women doctors is about 2.3 times higher that of women in the general population, this may demonstrate that women who are highly professional and have positions where there is a high proportion of men colleagues have a high risk of depression. Thus, in the present study, the small number of women subjects, that is lower composition ratio of women 
Table 2. Adjusted odds ratio (OR) and 95\% confidence interval (CI) of major depression from multivariate logistic regression.

\begin{tabular}{lccc}
\hline & OR & $95 \% \mathrm{CI}$ & p-value \\
\hline Individual Parameters & & & \\
Gender (Men: 0, Women: 1) & 7.009 & $2.387-20.584$ & $<0.001$ \\
Age (yrs) & 0.927 & $0.873-0.984$ & 0.014 \\
Professional position & & & \\
$\quad$ Professor (standard) & & \\
Associate professor & & \\
Lecturer & & \\
Assistant & & \\
Teaching experiences (yrs)
\end{tabular}

Work Situation (WSQ)

Working hours per week

Homework (No: 0, Yes 1)

Conditions of taking paid leave

Always (standard)

Often

Seldom

Job satisfaction level (\%)

0.945

$0.921-0.969$

$<0.001$

Job control level (\%)

Social Support (MSPSS)

Total Score

0.588

$0.376-0.921$

0.020

Family subscale

Significant other subscale

Friends subscale

Coping styles (COPE)

Self-distraction

Active coping

Denial

Substance use

1.453

$1.103-1.913$

0.008

Use of emotional support

Use of instrumental support

0.622

$0.399-0.969$

0.036

Behavioral disengagement

Venting

Positive reframing

Planning

Humor

Acceptance

Religion

1.813

$1.175-2.798$

0.007

Self-blame

1.808

$1.280-2.556$

0.001 
university faculty, as may have affected the women higher risk.

Our findings that women are seven times more at risk of developing depression than men are, and it can be considered extremely high. Also, coping style such as religion, self-blame, and substance use were related to risk for depression in our findings.

In the university, lower composition ratio of women university faculty, work style like highly professional may have affected the women higher risk.

Otsuka et al.'s study [30] [31] reported coping style that high levels of selfblame, denial, substance use, venting, self-distraction, religion, and behavioral disengagement were significantly associated with high levels of negative emotions, fatigue, and concentration/activity levels.

Lazarus [38] defined that psychological stress is an unfavorable person-environment relationship. From this perspective, it is thought that university teachers have been affected from stressful job's environment.

Under stressful circumstances, the types of effective coping used depend on the situation [39]. Therefore, coping flexibility, i.e., using different coping mechanisms depending on the circumstances, is emphasized upon [40]. It may be possible to lower the risk of depression by acquiring proper coping as shown from the results [40] of those who possess coping flexibility. In particular, the use of alcohol and drugs not only increases the risk of depression but also the risk of developing alcoholism and drug addiction [41]. Therefore, it is necessary to pay close attention to these matters and to communicate these dangers to teachers.

On the other hand, it was considered that elderly teachers have a low risk of depression. According to Hojo et al.'s study [42], it was reported that the general office young worker has much stress because of experience and knowledge, skill lack. So, it possibly because elderly teachers are adapted to university jobs, can skillfully arrange their work, and have the ability to perform multiple tasks.

The risk of depression was low for teachers who were satisfied with their jobs. However, due to changes in the environment surrounding university faculty members in recent years, the number of tasks outside the original duties of university faculty members, such as research and education, has increased [43]. The burden on individual faculty members is increasing, so measures are needed to improve job satisfaction. It is thought that reforming university organizations and businesses, and creating an environment where teachers can work easily help reduce the risk of depression.

The results of this study showed that the more social support toward a teacher has, the lower the risk of depression, and a previous study [44] supports this theory of social support. Enhancing sources of support both inside and outside the workplace is considered to be effective for reducing the risk of depression.

Implications by this study are several possible countermeasures that university faculty members can use against depression. First, such measures need to focus on mental health for women and young teachers, as they are at a high risk of depression. Second, they need to understand the needs of teachers and prepare the 
environment so that university faculty members can have higher job satisfaction. Third, measures should endeavor to build a social support system for university teachers, to convey the importance of receiving support, and to provide support to enable teachers to develop more than one stress coping to help them deal with stress appropriately. It is conceivable that universities can systematically tackle these matters and create a worker-friendly environment that may lead to reduced risk of depression among university faculty members.

The limitations of this research are as follows. This research surveyed only one university; therefore, the generalizability of the results is limited. The university that served as the field of research is a general university, and there may be different results for different faculties. In this survey, we did not inquire about the respondent's affiliated faculty, to prevent identification of individuals. Therefore, differences based on faculties could not be verified.

\section{Conclusion}

This study was to clarify Japanese university teachers' depression status assessed by the Patient Health Questionnaire-9 and its influence factors. For women, religion, self-blame, and substance use were risk factors of depression status. On the other hand, high job satisfaction level, higher age, use of instrumental support, and use of social support were factors that reduced the risk of depression. These findings suggested that in order to improve the depression status of university teachers, and to develop mental health measures for university faculty members, based on such risk factors are necessary in the future.

\section{Acknowledgements}

The authors wish to thank the Tokushima University Graduate School and its staff for their cooperation and assistance in undertaking this study.

\section{Conflict of Interests}

The author declares that there is no conflict of interests regarding the publication of this paper.

\section{Authors' Contributions}

MK contributed to study design, questionnaire survey, data input, drafting, and revising the manuscript. $\mathrm{KO}$ assisted in data analyses, and drafting the manuscript. TT assisted in the data analyses, interpretation, and reviewing the manuscript. TK participated in the interpretation, and reviewing the manuscript. YT participated in data input. BK made substantive intellectual contributions to the interpretation of data and drafts of the manuscript. All authors have read and approved the final manuscript.

\section{References}

[1] World Health Organization (2008) The Global Burden of Disease: 2004 Update. Geneva: World Health Organization. 
http://www.who.int/healthinfo/global_burden_disease/2004_report_update/en/

[2] Ito, H., Frank, R.G., Nakatani, Y. and Fukuda, Y. (2013) Mental Health Care Reforms in Asia: The Regional Health Care Strategic Plan: The Growing Impact of Mental Disorders in Japan. Psychiatric Services, 64, 617-619.

https://doi.org/10.1176/appi.ps.201200518

[3] Global Burden of Disease Study 2013 Collaborators (2015) Global, Regional, and National Incidence, Prevalence, and Years Lived with Disability for 301 Acute and Chronic Diseases and Injuries in 188 Countries, 1990-2013: A Systematic Analysis for the Global Burden of Disease Study 2013. The Lancet, 386, 743-800.

[4] Ministry of Health, Labour and Welfare (2014) Outline of Survey Results. http://www.mhlw.go.jp/english/database/db-hss/dl/sps_2014_01.pdf

[5] Ahsan, N., Abdullah, Z., Fie, D.Y.G. and Alam, S.S. (2009) A Study of Job Stress on Job Satisfaction among University Staff in Malaysia: Empirical Study. European Journal of Social Sciences, 8, 121-131.

[6] Sun, W., Wu, H. and Wang, L. (2011) Occupational Stress and Its Related Factors among University Teachers in China. Journal of Occupational Health, 53, 280-286. https://doi.org/10.1539/joh.10-0058-OA

[7] Winefield, A.H. and Jarrett, R. (2001) Occupational Stress in University Staff. International Journal Stress Management, 8, 285-298. https://doi.org/10.1023/A:1017513615819

[8] Shen, X., Yang, Y., Wang, Y., Liu, L., Wang, S. and Wang, L. (2014) The Association between Occupational Stress and Depressive Symptoms and the Mediating Role of Psychological Capital among Chinese University Teachers: A Cross-Sectional Study. Bio Med Central Psychiatry, 14, 329. https://doi.org/10.1186/s12888-014-0329-1

[9] Ministry of Education, Culture, Sports, Science and Technology (2015) Statistical Surveys of School Teacher. (In Japanese)

http://www.mext.go.jp/component/b_menu/other/_icsFiles/afieldfile/2015/03/27/1 356146_3.pdf

[10] Nie, Y. and Sun, H. (2016) Why Do Workaholics Experience Depression? A Study with Chinese University Teachers. Journal of Health Psychology, 21, 2339-2346. https://doi.org/10.1177/1359105315576350

[11] Miki, O. (2002) The Clinical Feature of Depression with Psychosomatic Medicine in Primary Care. Japanese Journal of Psychosomatic Medicine, 42, 585-591. (In Japanese)

[12] U.S. Preventive Services Task Force (2002) Screening for Depression: Recommendations and Rationale. Annals of Internal Medicine, 136, 760-764. https://doi.org/10.7326/0003-4819-136-10-200205210-00012

[13] Löwe, B., Kroenkeb, K., Herzoga, W. and Gräfea, K. (2004) Measuring Depression Outcome with a Brief Self-Report Instrument: Sensitivity to Change of the Patient Health Questionnaire (PHQ-9). Journal of Affective Disorders, 81, 61-66. https://doi.org/10.1016/S0165-0327(03)00198-8

[14] Kroenke, K., Spitzer, R.L. and Williams, J.B.W. (2001) The PHQ-9: Validity of a Brief Depression Severity Measure. Journal of General Internal Medicine, 16, 606613. https://doi.org/10.1046/j.1525-1497.2001.016009606.x

[15] Spitzer, R.L., Kroenke, K., Williams, J.B.W. and Patient Health Questionnaire Study Group (1999) Validation and Utility of a Self-Report Version of PRIME-MD: The PHQ Primary Care Study. The Journal of American Medical Association, 282, 1737-1744. https://doi.org/10.1001/jama.282.18.1737

[16] Spitzer, R.L., Williams, J.B., Kroenke, K., Linzer, M., deGruy 3rd, F.V., Hahn, S.R., 
Brody, D. and Johnson, J.G. (1994) Utility of a New Procedure for Diagnosing Mental Disorders in Primary Care; The PRIME-MD 1000 Study. The Journal of American Medical Association, 272, 1749-1756. https://doi.org/10.1001/jama.1994.03520220043029

[17] Kataoka, M., Ozawa, K., Tanioka, T., Okuda, K., Chiba, S., Tomotake, M. and King, B. (2015) Gender Differences of the Influential Factors on the Mental Health Condition of Teachers in the A University. The Journal of Medical Investigation, 62, 56-61. https://doi.org/10.2152/jmi.62.56

[18] The Macarthur Foundation (2003) The Macarthur Initiative on Depression and Primary Care. http://www.depression-primarycare.org

[19] Nease Jr., D.E. and Maloin, J.M. (2003) Depression Screening: A Practical Strategy. The Journal of Family Practice, 52, 118-124.

http://www.coloradohealthpartnerships.com/provider/integrated/Depression-Scree ning-Article-D-Nease.pdf

[20] Muramatsu, K., Miyaoka, H., Kamijima, K., Muramatsu, Y., Yoshida, M., Otsubo, T. and Gejyo, F. (2007) The Patient Health Questionnaire, Japanese Version: Validity According to the Mini-International Neuropsychiatric Interview-Plus. Psychological Reports, 101, 952-960. https://doi.org/10.2466/pr0.101.3.952-960

[21] Martin, A., Rief, W., Klaiberg, A. and Braehler, E. (2006) Validity of the Brief Patient Health Questionnaire Mood Scale (PHQ-9) in the General Population. General Hospital Psychiatry, 28, 71-77. https://doi.org/10.1016/j.genhosppsych.2005.07.003

[22] Mitchell, A.J., Yadegarfar, M., Gill, J. and Stubbs, B. (2016) Case Finding and Screening Clinical Utility of the Patient Health Questionnaire (PHQ-9 and PHQ-2) for Depression in Primary Care: A Diagnostic Meta-Analysis of 40 Studies. The British Journal of Psychiatry, 2, 127-138. https://doi.org/10.1192/bjpo.bp.115.001685

[23] Wu, S.V. (2014) Rapid Screening of Psychological Well-Being of Patients with Chronic Illness: Reliability and Validity Test on WHO-5 and PHQ-9 Scales, Depression Research and Treatment. Depression Research and Treatment, 2014, Article ID: 239490. https://doi.org/10.1155/2014/239490

[24] Lamers, F., Jonkers, C.C., Bosma, H., Penninx, B.W., Knottnerus, J.A. and van Eijk, J.T. (2008) Summed Score of the Patient Health Questionnaire-9 Was a Reliable and Valid Method for Depression Screening in Chronically Ill Elderly Patients. Journal of Clinical Epidemiology, 61, 679-687. https://doi.org/10.1016/j.jclinepi.2007.07.018

[25] Dahlem, N.W., Zimet, G.D. and Walker, R.R. (1991) The Multidimensional Scale of Perceived Social Support: A Confirmation Study. Journal of Clinical Psychology, 47, 756-761.

https://doi.org/10.1002/1097-4679(199111)47:6<756::AID-JCLP2270470605>3.0.CO $\underline{; 2-\mathrm{L}}$

[26] Zimet, G.D., Powell, S.S., Farley, G.K., Werkman, S. and Berkoff, K. (1990) Psychometric Characteristics of the Multidimensional Scale of Perceived Social Support. Journal of Personality Assessment, 55, 610-617. https://doi.org/10.1080/00223891.1990.9674095

[27] Zimet, G.D., Dahlem, N.W. Zimet, S.G. and Farley, G.K. (1988) The Multidimensional Scale of Perceived Social Support. Journal of Personality Assessment, 52, 30-41. https://doi.org/10.1207/s15327752jpa5201_2

[28] Iwasa, H., Gondo, Y., Masui, Y., Inagaki, H., Kawai, C., Otsuka, R., Ogawa, M., Takayama, M., Imuta, H. and Suzuki, T. (2007) Reliability and Validity of "Social Support Scale", Japanese Language Edition: Investigation Targeting Middle and Old Age. Indicators of Social Welfare, 54, 26-33. (In Japanese) 
[29] Carver, C.S. (1997) You Want to Measure Coping but Your Protocol's Too Long: Consider the Brief Cope. International Journal of Behavioral Medicine, 4, 92-100. https://doi.org/10.1207/s15327558ijbm0401_6

[30] Otsuka, Y. (2008) The COPE Inventory: A Theoretically Based Coping Questionnaire. Hiroshima Psychological Research, 8, 121-128. (In Japanese)

[31] Otsuka, Y., Sasaki, T., Iwasaki, K. and Mori, I. (2009) Working Hours, Coping Skills, and Psychological Health in Japanese Daytime Workers. Industrial Health, 47, 22-32. https://doi.org/10.2486/indhealth.47.22

[32] Kroenke, K., Strine, T.W., Spitzer, R.L., Williams, J.B., Berry, J.T. and Mokdad, A.H. (2009) The PHQ-8 as a Measure of Current Depression in the General Population. Journal of Affective Disorders, 114, 163-173. https://doi.org/10.1016/j.jad.2008.06.026

[33] Haratani, T., Tsuchiya, M., Izawa, S. and Kurabayashi, L. (2015) The Questionnaire Survey of Psychosocial Stress and Depressive Symptoms among Workers. Specific research reports of National Institute of Occupational Safety and Health, 45, 53-60. (In Japanese)

[34] Kidger, J., Brockmana, R., Tilling, K., Campbell, R., Ford, T., Araya, R., King, M. and Gunnell, D. (2016) Teachers' Wellbeing and Depressive Symptoms, and Associated Risk Factors: A Large Cross Sectional Study in English Secondary Schools. Journal of Affective Disorders, 192, 76-82. https://doi.org/10.1016/j.jad.2015.11.054

[35] Kawakami, N., Takeshima, T., Ono, Y., Uda, H., Hata, Y., Nakane, Y., Nakane, H., Iwata, N., Furukawa, T.A. and Kikkawa, T. (2005) Twelve-Month Prevalence, Severity, and Treatment of Common Mental Disorders in Communities in Japan: Preliminary Finding from the World Mental Health Japan Survey 2002-2003. Psychiatry and Clinical Neurosciences, 59, 441-452. https://doi.org/10.1111/j.1440-1819.2005.01397.x

[36] Kato, M., Chayama, H. and Hoshigoe, A. (2012) Analysis on Ratio of Women in Science in Japan. National Institute of Science and Technology Policy. (In Japanese) http://www.nistep.go.jp/wp/wp-content/uploads/mat209j.pdf

[37] Schernhammer, E.S. and Colditz, G.A. (2004) Suicide Rates among Physicians: A Quantitative and Gender Assessment (Meta-Analysis). American Journal of Psychiatry, 161, 2295-2302. https://doi.org/10.1176/appi.ajp.161.12.2295

[38] Lazarus, R.S. (1993) From Psychological Stress to the Emotions: A History of Changing Outlooks. Annual Review of Psychology, 44, 1-22.

https://doi.org/10.1146/annurev.ps.44.020193.000245

[39] Nakamura, S. and Otsuka, Y. (2014) The Effect of Metacognition and Self-Focused Attention on Coping Flexibility and Depression. The Japanese Journal of Behavioral Medicine, 20, 77-84. (In Japanese)

[40] Kato, T. (2001) The Relationship between Flexibility of Coping to Stress and Depression. The Japanese Psychological Association, 72, 57-63. (In Japanese) https://doi.org/10.4992/jjpsy.72.57

[41] Grant, B.F., Stinson, F.S., Dawson, D.A., Chou, S.P., Dufour, M.C., Compton, W., Pickering, R.P. and Kaplan, K. (2004) Prevalence and Co-Occurrence of Substance Use Disorders and Independent Mood and Anxiety Disorders: Results from the National Epidemiologic Survey on Alcohol and Related Conditions. Archives of General Psychiatry, 61, 807-816. https://doi.org/10.1001/archpsyc.61.8.807

[42] Hojo, K. and Kagawa, M. (2005) An Analysis of Occupational Stress and Coping with Stress-On the Relation of Managerial Positions-. Japanese Journal of Psychosomatic Internal Medicine, 9, 25-30. (In Japanese)

[43] Pan, B., Shen, X., Liu, L., Yang, Y. and Wang, L. (2015) Factors Associated with Job 
Satisfaction among University Teachers in Northeastern Region of China: A Cross-Sectional Study. International Journal of Environmental Research Public Health, 12, 12761-12775. https://doi.org/10.3390/ijerph121012761

[44] Hori, M. and Otsuka, Y. (2010) Depressive Mood, and Its Relationship to Job Demand, Job Control, and Social Support among Japanese Junior and Senior High School Teachers. The Japanese Journal of Stress Sciences, 25, 221-229. (In Japanese)

Submit or recommend next manuscript to SCIRP and we will provide best service for you:

Accepting pre-submission inquiries through Email, Facebook, LinkedIn, Twitter, etc. A wide selection of journals (inclusive of 9 subjects, more than 200 journals)

Providing 24-hour high-quality service

User-friendly online submission system

Fair and swift peer-review system

Efficient typesetting and proofreading procedure

Display of the result of downloads and visits, as well as the number of cited articles Maximum dissemination of your research work

Submit your manuscript at: http://papersubmission.scirp.org/

Or contact ojpsych@scirp.org 